
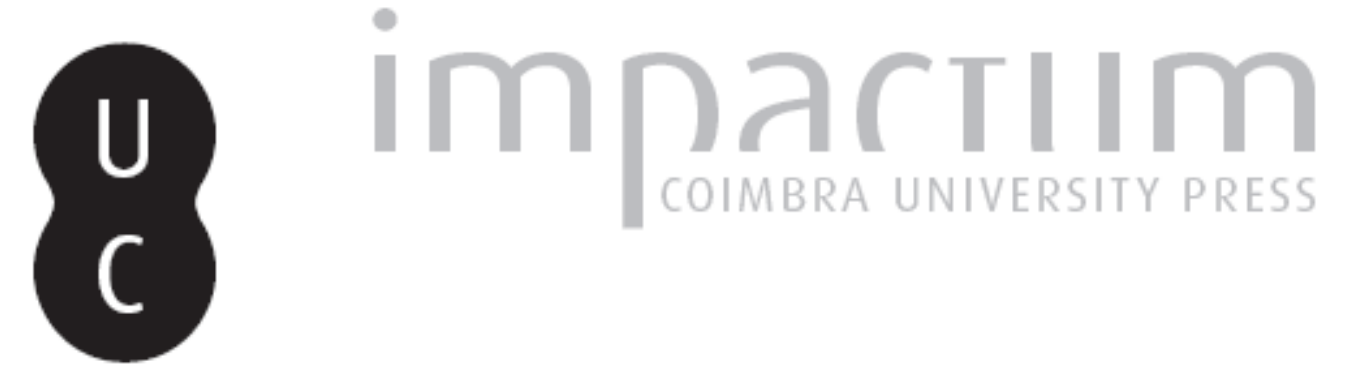

\title{
Os feitos de D. Fuas Roupinho na Crónica de 1419
}

\section{Autor(es): $\quad$ Silva, Tiago João Queimada e}
Publicado por: Faculdade de Letras da Universidade de Coimbra, Instituto de Hstória Económica e Social

URL persistente:

URI:http://hdl.handle.net/10316.2/28048

DOI:

DOI:http://dx.doi.org/10.14195/0870-4147_43_4

Accessed : $\quad$ 26-Apr-2023 11:05:27

A navegação consulta e descarregamento dos títulos inseridos nas Bibliotecas Digitais UC Digitalis, UC Pombalina e UC Impactum, pressupõem a aceitação plena e sem reservas dos Termos e Condições de Uso destas Bibliotecas Digitais, disponíveis em https://digitalis.uc.pt/pt-pt/termos.

Conforme exposto nos referidos Termos e Condições de Uso, o descarregamento de títulos de acesso restrito requer uma licença válida de autorização devendo o utilizador aceder ao(s) documento(s) a partir de um endereço de IP da instituição detentora da supramencionada licença.

Ao utilizador é apenas permitido o descarregamento para uso pessoal, pelo que o emprego do(s) título(s) descarregado(s) para outro fim, designadamente comercial, carece de autorização do respetivo autor ou editor da obra.

Na medida em que todas as obras da UC Digitalis se encontram protegidas pelo Código do Direito de Autor e Direitos Conexos e demais legislação aplicável, toda a cópia, parcial ou total, deste documento, nos casos em que é legalmente admitida, deverá conter ou fazer-se acompanhar por este aviso.

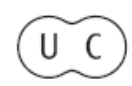





\title{
Os feitos de D. Fuas Roupinho na Crónica de 1419
}

\author{
Tiago João Queimada e Silva \\ Mestre em História da Idade Média, Faculdade de Letras da Universidade de Coimbra \\ tiagosilva1169@gmail.com
}

Resumo:

O presente estudo centra-se em dois capítulos específicos da Crónica de Portugal de 1419 , dedicados às proezas de $\mathrm{D}$. Fuas Roupinho. Procedi a um exame aprofundado das narrativas que ele protagoniza na dita crónica, tendo como objectivo uma melhor compreensão da funcionalidade que esses relatos incorporam, quando enquadrados nos propósitos político-ideológicos globais da crónica régia quatrocentista. Por outro lado, tentei elaborar um curto ponto de situação relativamente ao recente processo de credibilização histórica da personagem de Fuas Roupinho, encetado por vários historiadores contemporâneos, e fornecer uma contextualização geral do fundo histórico que terá servido de matéria-prima para a formação do relato da Crónica de 1419, fazendo uso de elementos revelados por outros investigadores. Por fim, procurei avançar novos dados relativos à suposta identidade histórica do mítico "almirante" luso.

Palavras chave:

Cronística Medieval; Crónica de Portugal de 1419; Fuas Roupinho; Dinastia de Avis.

\section{Abstract:}

This study focuses on two specific chapters of the 1419 Crónica de Portugal (Chronicle of Portugal), dedicated to D. Fuas Roupinho's heroic deeds. I made a thorough examination of the chronicle's narratives where he played the leading role, aiming at a better understanding of the functionality that these reports incorporate, when framed in the global political-ideological purposes of the $\mathrm{XV}^{\text {th }}$ century royal chronicles. On the other hand, I tried to draw up a short report on the state of the art regarding the recent process of making credible the historic character of D. Fuas Roupinho, initiated by a number of contemporary historians, and provide a general context of the historical background that has served as raw material for the formation of the account of the 1419 Chronicle, making use of elements revealed by other researchers. Finally, I tried to unveil new data on the supposed historical identity of the mythical Lusitanian "admiral".

Keywords:

Medieval Chronicles; 1419 Chronicle of Portugal; Fuas Roupinho; Avis Dynasty. 
A Crónica de Portugal de 1419 sinaliza o nascimento de uma sólida tradição cronística régia, meio de transmissão de um discurso historiográfico bastante definido, consistente e sensível aos desígnios políticos da recém-empossada dinastia de Avis. Por outro lado, ainda em relação às necessidades legitimadoras desta dinastia, a imagem idealizada de D. Afonso Henriques, como um semi-santo paladino da Cristandade, é plasmada no discurso historiográfico régio para prevalecer, a partir daí, sobre as representações alternativas do primeiro rei português, nomeadamente, as criadas em meios aristocráticos.

No entanto, no seio da narrativa do reinado de Afonso Henriques na Crónica de 1419, constam dois capítulos cuja peculiaridade nos chama imediatamente a atenção, ao "roubarem" momentaneamente o protagonismo ao monarca luso. Neles se reportam os feitos de Fuas Roupinho, apresentado como senhor de Porto de Mós e almirante de uma frota portuguesa que cumpriu um papel importante nos combates marítimos e acções de pirataria contra os muçulmanos, nos inícios da década de 80 do século XII.

Com este artigo, pretendo clarificar alguns aspectos atinentes ao relato dos feitos de Fuas Roupinho na Crónica de 1419, bem como aventar algumas propostas sobre o significado ideológico que estas narrativas incorporam, no que respeita ao discurso historiográfico da dinastia de Avis, ou seja, tentar perceber em que medida elas se articulam com os propósitos legitimadores deste texto, produzido a mando do filho de D. João I, o então Infante D. Duarte.

\section{Fuas Roupinho na Crónica de 1419}

Como já foi afirmado, dois capítulos da Crónica de 1419 são consagrados aos feitos de Fuas Roupinho, que era, segundo a mesma crónica, o senhor de Porto de Mós ${ }^{1}$. De acordo com esta compilação, "Gani”, rei da terra "onde ora he Cárceres e Valemça”, acompanhado do seu irmão, liderou uma expedição

1 Adelino Almeida Calado (ed.), Crónica de Portugal de 1419, Aveiro, Universidade de Aveiro, 1998, Caps. 41 e 42, p. 76-79. Sobre esta crónica, veja-se Filipe Alves Moreira, A Crónica de Portugal de 1419: Fontes, Estratégias e Posteridade, Porto, Faculdade de Letras do Porto, 2010; Artur de Magalhães Basto (ed.), Crónica de Cinco Reis de Portugal, Porto, Livraria Civilização, 1945; Idem, Estudos. Cronistas e crónicas antigas. Fernão Lopes e a “Crónica de 1419”, Coimbra, Imprensa da Universidade, 1960; Carlos da Silva Tarouca (ed.), Crónicas dos sete primeiros reis de Portugal, Lisboa, Academia Portuguesa de História, 3 vol., 1952-1953; Luís Krus, "Crónica de Portugal de 1419”, in Giulia Lanciani, e Giuseppe Tavani (org. e coord.), Dicionário da Literatura Medieval Galega e Portuguesa, Lisboa, Caminho, 1993, p. 185-186; Luís Filipe Lindley Cintra (ed.), Crónica Geral de Espanha de 1344, Vol. I (Introdução), Lisboa, Academia Portuguesa de História, 1951, p. CDV-CDX. Designarei, de agora em diante, a Crónica de 1419 pela sigla C1419. 
em terra de cristãos, atingindo o seu exército o termo de Porto de Mós. Ao tomar conhecimento da aproximação dos muçulmanos, Fuas Roupinho decide abandonar o local, deixando aí homens que pudessem defender o castelo, e esconde-se na serra “que chamavom da Mondega”. Daqui envia, de seguida, uma mensagem aos habitantes de Alcanede e de Santarém, na qual lhes pede que o auxiliem no combate contra o rei muçulmano que se dirige a Porto de Mós. Os mouros investem sobre o dito castelo, convencidos de que a tarefa a que se propunham seria facilmente concretizada, enquanto os homens que estavam escondidos com Fuas Roupinho lhe aconselham que vá imediatamente em socorro do seu castelo. O nobre português dirige então um discurso aos seus homens, onde lhes explica o seu plano, o qual consistia em esperar pelo anoitecer, quando os inimigos se encontram entorpecidos pelo sono, acometendo-os nessa altura. Por fim, o plano de Fuas Roupinho foi cumprido, obtendo os cristãos a vitória e aprisionando o rei Gani e o seu irmão, a 22 de Maio de 1218 (AD 1180), de acordo com a indicação da crónica. Ambos foram levados a Coimbra e apresentados perante Afonso Henriques, que outorga muitas “merçees"a Fuas Roupinho, em consideração pelo seu feito. ${ }^{2}$

A crónica prossegue, no capítulo imediatamente posterior, com as outras proezas de D. Fuas, que, à época, pousava com o rei em Coimbra. Por essa altura, os habitantes de Lisboa escrevem uma missiva a Afonso Henriques, na qual the dão a conhecer que a cidade era assolada por uma frota de mouros, comandada por "Ferneio d·Alphamim", requerendo os lisboetas, por esse motivo, o auxílio régio. O rei encarrega Fuas Roupinho de ir a Lisboa, onde deveria armar uma esquadra para combater os muçulmanos, dando, ao mesmo tempo, instruções aos habitantes da cidade para que seguissem as ordens do recém-nomeado almirante. Depois de armada a frota cristã, ela segue para o cabo Espichel, onde encontra as galés mouras. Trava-se, então, uma batalha naval, de onde saem triunfantes os cristãos, em Julho da era de 1218 (AD 1180).

Depois de retornar a Lisboa, Fuas Roupinho escreve ao monarca português, comunicando-lhe a sua vontade, coincidente com a dos habitantes de Lisboa, de encetar uma guerra marítima contra os muçulmanos, pedido ao qual o rei prontamente acede. A frota liderada por D. Fuas parte para o Algarve, onde “coreo a costa", admitindo o cronista, neste ponto, não ter encontrado fontes escritas que fornecessem quaisquer pormenores sobre esta operação militar. De seguida, a frota portuguesa ataca Ceuta, de onde traz grande espólio

\footnotetext{
2 C1419, Cap. 41, p. 76-77.
} 
para Lisboa. Inebriados pelas vitórias alcançadas, Fuas Roupinho e os seus homens decidem repetir o ataque à cidade norte-africana, sendo, no entanto, interceptados no estreito de Gibraltar por 54 galés muçulmanas, que derrotam as embarcações cristãs e trazem a morte do próprio "almirante" português, em 17 de Outubro da mesma era de 1218 (AD 1180).

Tenho de realçar que se desconhece a fonte do autor da Crónica de 1419 para a secção dedicada aos feitos de D. Fuas. Enquanto Maria Fernanda Espinosa Gomes da Silva indaga se estes episódios se não teriam transmitido de forma oral até à sua incorporação nas crónicas ${ }^{4}$, Luís Krus pensa que os relatos das façanhas do "almirante" poderiam constar em "escritos monásticos hoje desaparecidos", que teriam sido utilizados pelo cronista de 1419 . Estes relatos seriam desenvolvidos, provavelmente, no seio do Mosteiro de Alcobaça, culminando este processo com a criação da Lenda da Nazaré, onde Fuas Roupinho é salvo da morte pela Virgem. ${ }^{5}$ Há, no entanto, uma particularidade do relato dos feitos de Fuas Roupinho que me faz pôr em causa a proposta de Luís Krus: como já foi antes notado ${ }^{6}$, esta secção da crónica carece de um discurso de guerra santa, verificando-se, ademais, a inexistência de qualquer referência explícita à intervenção divina no enredo, contrastando com o que se verifica no resto da narrativa do reinado de Afonso I. Apesar de salvaguardar a imagem encomiástica da realeza, posto que a posição de Afonso Henriques como líder inquestionável da guerra contra o Islão não é relativizada pela audácia combativa de Fuas Roupinho, penso que um texto redigido num meio monástico, segundo a hipótese de Luís Krus, dificilmente prescindiria da ideologia e terminologia cruzadística, existentes em outros textos clericais que foram aproveitados pela Crónica de 1419, sendo, em consequência, a ideologia de guerra santa um tópico que perpassa a totalidade da narrativa do reinado de Afonso Henriques na crónica quatrocentista. Por outro lado, caso a sua fonte patenteasse, de facto, um discurso de guerra santa, parece-me altamente improvável que o cronista da corte de Avis o fosse escamotear totalmente,

3 C1419, Cap. 42, p. 78-79.

4 Maria Fernanda Espinosa Gomes da Silva, "Roupinho, Fuas (século XII), in Joel Serrão (dir.), Dicionário de História de Portugal, Vol. III, Porto, Livraria Figueirinhas/Iniciativas Editoriais, 1971, p. 696.

5 Luís Krus, "Roupinho, D. Fuas", in José Costa Pereira (coord.), Dicionário Enciclopédico da História de Portugal, Vol. II, Lisboa, Publicações Alfa - Selecções do Reader's Digest, 1990, p. 188; Frei Bernardo de Brito, Monarquia Lusitana, Segunda Parte, Lisboa, 1609, fl. 272r-279v.

6 Tiago João Queimada e Silva, As metamorfoses de um guerreiro: Afonso Henriques na cronística medieval, Coimbra, Faculdade de Letras da Universidade de Coimbra, 2011, p. 123-124, nota 453. 
especialmente se tivermos em conta as características discursivas gerais do texto e o trabalho de reescrita que o cronista exerceu sobre as suas fontes.

Enfim, fica claro que o cronista usou, efectivamente, uma fonte escrita para o relato das proezas de Fuas Roupinho, algo que é denunciado pelo próprio autor da crónica, não só ao indicar datações absolutas para os eventos narrados, mas também quando admite que não achou algo "em esprito" que reportasse os ataques de D. Fuas no Algarve ${ }^{7}$, o que demonstra que a inexistência de uma fonte escrita consiste num estado de excepção. Ainda assim, a fonte do cronista de 1419 para os feitos de Fuas Roupinho permanece obscura.

\section{Uma personagem histórica?}

As acções de D. Fuas Roupinho, conforme o explicitado na Crónica de 1419, têm lugar em 1180, fornecendo esta crónica um enquadramento cronológico que permitiu a vários autores conceder alguma historicidade ou, pelo menos, verosimilhança, ao relato da crónica quatrocentista, algo já anteriormente notado por Luís Krus ${ }^{8}$. Durante os finais da década de 70 e os inícios de 80 do século XII verifica-se um recrudescimento dos confrontos entre o reino luso e o império almóada. Registe-se, a título de exemplo, o vitorioso fossado que o Infante D. Sancho lidera até Triana, nos arredores de Sevilha, em 1178, o cerco que o filho do califa almóada pôs sobre Abrantes um ano depois, ou, ainda, o cerco de Évora e a destruição do castelo de Coruche, em 1180 ou $1181 .{ }^{9}$

7 C1419, Cap. 42, p. 79.

8 Luís Krus, "Roupinho, D. Fuas", p. 188.

9 Cf. "Annales D. Alfonsi Portugallensium Regis", em Monica Blöcker Walter, in Alfons I von Portugal: Studien zu Geschichte und Sage des Begrunders der Portugiesische Unbhägigkeit, Zürich, Fretz und Wasmuth Verlag, 1966, Eras 1216, 1217 e 1218, p. 159; Ambrosio Huici Miranda (trad.), Colección de Crónicas Árabes de la Reconquista, Tomo I: Los Almohades, Vol. II: Al-Bayān Al-Mugrib Fi Ijtisār Ajbār Muluk Al-Andalus Wa Al-Magrib, Tetuán, Editora Marroquí, 1953, p. 39-40. Designarei esta crónica árabe, de agora em diante, Al-Bayān, seguido da paginação de acordo com a tradução de Huici Miranda. Veja-se, ademais, José Mattoso, D. Afonso Henriques, Lisboa, Temas \& Debates, 2007, p. 363-365, 367-368; Idem, "Dois séculos de vicissitudes políticas", in José Mattoso (dir.), História de Portugal, Vol. 2: A Monarquia Feudal, Lisboa, Editorial Estampa, 1997, p. 82-84; Maria João Violante Branco, D. Sancho I: o Filho do Fundador, Lisboa, Círculo de Leitores, 2006, p. 82-83, 90; Alexandre Herculano, História de Portugal, Tomo III, Lisboa, Aillaud-Bertrand, $8^{\text {a }}$ edição, s/d, p. 106-108, 112-114; Mário Jorge Barroca, "História das Campanhas", in Manuel Themudo Barata, e Nuno Severiano Teixeira (dir.), Nova História Militar de Portugal, Vol. 1, Lisboa, Círculo de Leitores, 2003, p. 47-49; Maria Cristina Pimenta, Guerras no Tempo da Reconquista. 1128-1249, Lisboa, Quidnovi, 2008, p. 48; Ambrosio Huici Miranda, "Los Almohades en Portugal”, Anais da Academia Portuguesa de História, II ${ }^{a}$ Série, Vol. 5 (1954), p. 27. 
No entanto, estes anos são marcados não somente por uma intensificação da prática militar, mas também por uma aparente diversificação da mesma, como se pode inferir da multiplicação de referências cronísticas a acções de guerra marítima e de pirataria costeira. Não se trata de algo completamente original mas, pela primeira vez, temos indícios que nos dizem que o jovem reino português patrocinava activamente esta forma de fazer a guerra ${ }^{10} \mathrm{e}$ inclusivamente teria meios para armar uma esquadra que chegou a atingir uma dimensão considerável, disputando a primazia com o império almóada. ${ }^{11}$ Com efeito, o surgimento de dois estados, o português e o almóada, cujas bases assentavam no espaço Atlântico, transformou essa área marítima numa autêntica "zona de fronteira" e, como tal, o jogo da guerra abrange também esse meio ${ }^{12}$.

Tendo isto em conta, vejamos, então, como outros autores procuraram reconstituir e contextualizar o percurso do "almirante"13, que ganha, assim, uma dimensão histórica.

Presumivelmente, em 1179, Fuas Roupinho, líder de uma esquadra de galés supostamente armada sob o patrocínio régio, entra pelo Guadalquivir e ataca os arredores de Sevilha. Em represália a este assalto, Ganim Ibn Mardanish, comandante da esquadra de Ceuta, saqueia os arrabaldes de Lisboa, despoletando mais um ataque de Fuas Roupinho, desta feita sobre a ilha de Saltes. No ano seguinte, Ganim e um seu irmão, Abu-1-'Ula, tentam conquistar Porto de Mós, sendo derrotados, aprisionados e levados por Fuas Roupinho num cortejo triunfal em Coimbra. Além disso, neste mesmo ano, D. Fuas, liderando uma frota armada em Lisboa, derrota 9 galés almóadas ao largo do Cabo Espichel. Em 1181, o "almirante" e a sua esquadra, que à época já contaria com cerca de 40 navios, assolam não somente as costas algarvias, mas também praças importantes do Norte de África, como é o caso de Ceuta. Num destes ataques, a esquadra olisiponense é interceptada por uma frota almóada de 54 navios,

${ }^{10}$ Luís Miguel Duarte, "A Marinha de Guerra Portuguesa”, in Nova História Militar..., cit., Vol. 1, p. 296, considera que os primeiros passos na construção de uma marinha de guerra portuguesa foram dados, precisamente, durante o reinado de D. Afonso Henriques.

${ }^{11}$ José Mattoso, D. Afonso Henriques, p. 366; Maria João Violante Branco, cit., p. 91-92; Luís Miguel Duarte, “A Marinha...”, cit., p. 290-297; Christophe Picard, L'océan Atlantique musulman: De la conquête arabe à l'époque almohade, Paris, Maisonneuve \& Larose, 1997, p. $125,358-359$.

${ }^{12}$ Cf. Idem, ibidem, p. 354.

${ }^{13}$ Christophe Picard, Ibidem, p. 354, considera histórica a informação da C1419, segundo a qual Fuas Roupinho teria sido nomeado almirante da frota olisiponense, cf. C1419, Cap. 42, p. 79. No entanto, penso que a crónica provavelmente investe sobre a personagem de D. Fuas, de forma retrospectiva, um cargo mais tardio, visto que o almirantado apenas surge documentado no reinado de D. Dinis. Cf. Luís Miguel Duarte, “A Marinha...”, cit., p. 299. 
que acaba por derrotar os portugueses, afundando 20 das suas embarcações e matando o próprio D. Fuas Roupinho. ${ }^{14}$

Desta forma, podemos ver que os combates de 1180-1181 são hoje conhecidos graças ao eco que deixaram na Crónica de 1419, tornando este texto numa fonte importante para a reconstituição histórica esboçada pelos historiadores contemporâneos, a qual adquire contornos mais detalhados na recente biografia de D. Sancho I, da autoria de Maria João Violante Branco. Neste seu trabalho, a autora integra as incursões de Fuas Roupinho num contexto de crescente hostilidade entre o reino português e o império almóada, após o culminar de umas curtas tréguas que haviam sido estabelecidas em $1173 .{ }^{15}$ Ela dá-nos conta das sucessivas incursões de $1179^{16}$, que precederam as acções relatadas na Crónica de 1419; precisa, ancorada noutras fontes, que a frota de D. Fuas seria composta por 40 navios; por fim, data a derrota da esquadra portuguesa em 1181, não em 1180, como é afirmado na Crónica de 1419, informando, ademais, que 20 navios lusos haviam sido afundados nesta batalha, informação igualmente ausente da crónica quatrocentista. Ainda relativamente a este último combate de D. Fuas Roupinho, Maria João Violante Branco ressalva que não é certo que ele tenha tido lugar perto do estreito de Gibraltar, como diz a Crónica de 1419, sendo também possível que ele se desse ao largo do cabo de S. Vicente, como propôs Cristophe Picard, ou mesmo do Cabo Espichel, tal como proposto por Ambrosio Huici Miranda. ${ }^{17} \mathrm{Em}$ adição ao já referido, a identidade de "Gani" e do seu irmão foi também clarificada pelos historiadores contemporâneos. Tudo isto permitiu investir alguma verosimilhança sobre o relato da Crónica de 1419, não obstante a cronologia tardia da fonte em

${ }^{14}$ Segui, como fonte principal, Maria João Violante Branco, cit., p. 89. Veja-se também José Mattoso, D. Afonso Henriques, p. 365-366; Alexandre Herculano, cit., Tomo III, p. 108, 113; Luís Miguel Duarte, “A Marinha...”, p. 296-297; Luís Krus, "Roupinho, D. Fuas", p. 187-188; Manuel Sílvio Alves Conde, "Sesimbra, sobre a costa do mar (séculos XII-XIII), Arquipélago-História, $2^{\mathrm{a}}$ série, VII (2003) p. 253; Christophe Picard, L'océan Atlantique..., p. 125, 351-359. Neste último trabalho, Christophe Picard chega ao ponto de questionar se Ganim Ibn Mardanish, ao atacar Porto de Mós, não teria o propósito antecipado de capturar Fuas Roupinho, que seria, segundo o seu raciocínio, uma das principais ameaças para o poderio marítimo almóada. Do mesmo autor, veja-se também Le Portugal Musulman: VIII ${ }^{e}$-XIII ${ }^{e}$ siècles, Paris, Maisonneuve \& Larose, 2000, p. 105.

${ }^{15}$ Maria João Violante Branco, cit., p. 87-93; José Mattoso, D. Afonso Henriques, p. 339.

${ }^{16}$ Isto é, o ataque da esquadra portuguesa nos arredores de Sevilha, a investida de Ganim Ibn Mardanish sobre Lisboa e as represálias dos portugueses na ilha de Saltes.

${ }^{17}$ Maria João Violante Branco, cit., p. 89; Christophe Picard, L'océan Atlantique..., cit., p. 355-356; Ambrosio Huici Miranda, "Los Almohades...", cit., p. 26. 
questão. Ainda assim, desconhecemos quão próxima seria a fonte do cronista relativamente aos eventos que relata.

De uma forma geral, esta reconstituição resulta da conjugação entre o relato da Crónica de 1419 e uma fonte árabe conhecida como Al-Bayān Al-Mugrib, redigida por Ibn 'Idārī Al-Marrākušī nos inícios do século XIV ${ }^{18}$. Além de mencionar a intensificação dos ataques dos homens de Ibn al-Rink por terra e por mar, este texto narra a entrega do comando da esquadra de Ceuta a Ganim Ibn Mardanish, bem como o ataque que este empreende sobre Lisboa e as represálias sofridas em Saltes, acontecimentos que tiveram lugar, segundo o cronista muçulmano, no ano 575 da Hégira (entre 8 de Junho de 1179 e 28 de Maio de 1180). Integra, também, uma lacónica menção à captura de Ganim e Abu-1-'Ula e à pesada derrota infligida sobre os muçulmanos, que levou a que os cristãos se apoderassem de várias galés, eventos ocorridos em meados de Junho de $1180^{19}$. O processo que levou ao resgate dos irmãos é também descrito por Ibn 'Idārī, ao mesmo tempo que menciona os estragos que os cristãos fariam por esse ano nas costas muçulmanas. Por fim, o Al-Bayān refere que a esquadra de Ceuta, comandada por 'Abd Allāh b. Yāmi enquanto Ganim não era resgatado, e a de Sevilha, capitaneada por Abu-1-'Abbās, partem para a região de Silves, a 31 de Maio de $1181^{20}$, e encontram a frota lisboeta no mesmo local onde Ganim Ibn Mardanish fora capturado. Culminou este recontro numa estrondosa derrota para os cristãos, com o aprisionamento de 1800 cativos, além de 20 embarcações e um valioso espólio..$^{21}$

Basicamente, a totalidade dos eventos não relatados pela Crónica de 1419 mas mencionados pela historiografia contemporânea encontra-se no texto de Ibn 'Idārī. Os pontos de contacto entre a crónica muçulmana e a cristã resumem-se à menção das incursões levadas a cabo pelas frotas cristã e almóada, a captura de "Gani”, antropónimo que só pode corresponder a Ganim Ibn Mardanish ${ }^{22}$,

${ }^{18}$ Cf. nota 9.

${ }^{19}$ Isto é, em meados de Muharram do ano 576 da Hégira, cf. Al-Bayān, p. 38. A C1419 indica 22 de Maio de 1180 como data da derrota de Gani em Porto de Mós, como vimos, divergindo do Al-Bayān em poucos dias.

${ }^{20}$ Ou seja, a 15 de Muharram do ano 577 da Hégira, cf. Al-Bayān, p. 40 . A C1419 volta a divergir do Al-Bayān na datação da derrota final da esquadra olisiponense, posto que, na crónica quatrocentista, o desbarato dos cristãos tem lugar a 17 de Outubro de 1180.

${ }^{21}$ Al-Bayān, p. 32-41. Ambrosio Huici Miranda, "Los Almohades...", cit., p. 26-27; Idem, "Las campañas de Ya'qūb Al-Mansūr en 1190 y 1191", Anais da Academia Portuguesa de História, II ${ }^{\mathrm{a}}$ Série, Vol. 5 (1954), p. 73.

${ }^{22}$ Note-se, no entanto, que, apesar de o antropónimo Gani corresponder a uma personagem histórica, a C1419 identifica-o como "rei" de "Cárceres e Valemça”, algo que é rigorosamente anti-histórico, visto que, como já anteriormente foi realçado por Ambrosio Huici Miranda, 
e à derrota final dos cristãos, que dita a destruição da frota de Lisboa. Todas estas concordâncias, que permitiram um encadeamento dos dois textos para uma reconstrução histórica dos eventos, fornecem ao relato da Crónica de 1419 um determinado grau de historicidade. No entanto, em nenhuma parte da crónica árabe é mencionado o nome do líder da esquadra cristã, mantendo envolto na penumbra o nosso D. Fuas Roupinho.

Com efeito, por muito verosímil que o relato quatrocentista seja, não posso ignorar o facto de não possuir qualquer dado coevo que me permita asseverar a historicidade da personagem de Fuas Roupinho. Na verdade, ao abordar este tema, seria impossível esquivar-me à espinhosa questão da real identidade de D. Fuas, a quem os séculos elevaram a um estatuto semi-lendário, não fosse ele o protagonista da famosa Lenda da Nazaré. Desta forma, sabemos muito pouco da sua identidade, estando o seu nome ausente de toda a documentação coeva conhecida ${ }^{23}$. Tendo em conta a relação de proximidade que ele beneficiaria frente ao poder régio e aos órgãos concelhios de Lisboa, segundo as pistas deixadas pela Crónica de 1419, não deixa de ser intrigante a total ausência desta personagem na documentação oficial da época. Aliás, apesar de Fuas Roupinho ser comummente designado pela historiografia contemporânea como alcaide de Porto de Mós, o seu nome não consta em nenhum documento coevo proveniente desta localidade ${ }^{24}$.

Ganim Ibn Mardanish não era governador, muito menos rei, de Cáceres e Valência de Alcântara, cf. "Los Almohades...", cit., p. 26.

${ }^{23}$ A Doutora Leontina Ventura, no entanto, chamou-me a atenção para a existência de um indivíduo chamado Fuas, mencionado no testamento de Pedro Forjaz, homem influente no território de Coimbra, datado de 1156. Ainda assim, à parte da homonímia, por muito invulgar que o nome Fuas seja, não existem outros elementos que me permitam identificar o Fuas do testamento com o D. Fuas Roupinho da C1419. Cf. Avelino de Jesus da Costa, e Manuel Augusto Rodrigues (ed.), Livro Preto: cartulário da sé de Coimbra: edição crítica: texto integral, Coimbra, Arquivo da Universidade de Coimbra, 1999, doc. 276.

${ }^{24}$ Cf. Saul António Gomes, Porto de Mós: colectânea histórica e documental: séculos XII a XIX, Porto de Mós, Câmara Municipal, 2005. 
Vários autores identificaram-no com Fernão Gonçalves Churrichão, o "Farroupim" 25 . No entanto, já anteriormente ${ }^{26}$ fui obrigado a questionar esta proposta, pois, segundo a documentação existente, Fernão Gonçalves Churrichão teria vivido já na segunda metade do século XIII, visto que surge em três documentos datados de 1271, preservados na Catedral de Ourense ${ }^{27}$. Sabe-se, também, que Gonçalo Fernandes, o progenitor do "Farroupim", viveu nos inícios do século XIII ${ }^{28}$. Tenho, por conseguinte, de afastar a possibilidade de identificação de Fuas Roupinho com Fernão Gonçalves Churrichão, pese o facto de, infelizmente, não poder avançar nenhuma proposta alternativa sobre a identidade histórica do mítico "almirante" português.

Em suma, a concordância parcial verificada entre as fontes cristãs e árabes confere um carácter relativamente histórico não somente à relação dos eventos da Crónica de 1419, mas também, indirectamente, à peculiar personagem de Fuas Roupinho. Nesse sentido, é admissível considerar o "almirante" da crónica como um indivíduo histórico, o carismático líder de uma frota olisiponense, ao tempo que o jovem reino português se inteirava dos dividendos que poderiam advir do patrocínio de actos de guerra marítima. Como vimos, a mais recente historiografia portuguesa tem trilhado este caminho. Todavia, dois escolhos

${ }^{25}$ Joseph Piel, e José Mattoso (ed.), Portvgaliae Monvmenta Historica, Vol. II: Livro de Linhagens do Conde D. Pedro, Tomo 2, Nova Série, Lisboa, Academia das Ciências, 1980, 74G4-5, p. 177; Maria Fernanda Espinosa Gomes da Silva, "Roupinho, Fuas (século XII)", p. 696; Luís Krus, "Roupinho, Fuas”, p. 188; José Mattoso, D. Afonso Henriques, p. 365; Luís Miguel Duarte, “A Marinha...”, cit., p. 297. Maria Fernanda Espinosa Gomes da Silva sublinha que um Fernão Gonçalves confirma vários documentos régios entre 1137 e 1183, com maior frequência depois de 1150. No entanto, este confirmante deverá corresponder a Fernão Gonçalves, presumível conquistador de Beja em 1162 e filho primogénito de Gonçalo Dias, alcaide de Coimbra. Cf. José Mattoso, D. Afonso Henriques, p. 297; Idem, Ricos-homens, infanções e cavaleiros: a nobreza medieval portuguesa nos séculos XI e XII, $2^{\mathrm{a}}$ ed, Lisboa, Guimarães Editores, 1985, p. 184-187, 190, 211; Idem, A nobreza medieval portuguesa: a família e o poder, $4^{\text {a }}$ ed. rev., Lisboa, Estampa, 1994, p. 319-320; Leontina Ventura, "Os cavaleiros de Coimbra", comunicação inédita, apresentada ao Colóquio Internacional "Afonso Henriques: em torno da criação e consolidação das monarquias do Ocidente Europeu (sécs. XII-XIII). Identidades e Liminaridades", realizado de 14 a 16 de Dezembro de 2009, na Faculdade de Letras da Universidade de Lisboa; Idem, e Ana Santiago Faria (ed.), "Introdução", in Livro Santo de Santa Cruz: cartulário do Séc.XII, Coimbra, Instituto Nacional de Investigação Científica, 1990, p. 55-57; Mário Jorge Barroca, "História das Campanhas", p. 46.

${ }^{26}$ Tiago João Queimada Silva e, cit., p. 123-124, nota 453.

${ }^{27}$ Cf. Emilio Duro Peña (ed.), Documentos da Catedral de Ourense, A Coruña, Consello da Cultura Galega, 1996, docs. 70, 419, 419bis e 420.

${ }^{28}$ Eduardo Pardo de Guevara y Valdés, "De las viejas estirpes a las nuevas hidalguías. El entramado nobiliario gallego al fin de la Edad Media", Nalgures, Tomo III (2006), A Coruña: Asociación Cultural de Estudios Históricos de Galicia, p. 270, nota 20. 
me afastam de quaisquer conclusões mais assertivas: primeiro, a ausência de D. Fuas da documentação dos finais do século XII ou dos inícios do século XIII; segundo, o desconhecimento da fonte do cronista de 1419 para os feitos de Fuas Roupinho.

Para concluir, devo voltar a notar que os dois capítulos consagrados a D. Fuas Roupinho na narrativa do reinado de Afonso I na Crónica de 1419 são os únicos que privam o rei do protagonismo, exceptuando-se os dedicados ao seu filho, D. Sancho, que também acabam por cumprir o objectivo de exaltar a linhagem régia. Talvez derive disso o facto de o discurso de guerra santa, presente na totalidade da narrativa do reinado de Afonso Henriques, estar completamente ausente do relato dos feitos de Fuas Roupinho, assim como parece notório que o cavaleiro deve a sua primeira vitória, em Porto de Mós, à sua própria astúcia e não tanto à sua valentia ou devoção cristã, sendo estas últimas as principais virtudes da realeza lusa na Crónica de 1419. Além do mais, note-se que é a primeira vez, na cronística portuguesa, que a Reconquista se transfere para o mar, descrevendo-se actos de guerra marítima e de pirataria. Da mesma forma, pela primeira vez, as acções bélicas promovidas por portugueses chegam à costa norte-africana, ainda que não sob o comando directo do rei. A inclusão destes episódios no texto da Crónica de 1419 revela alguma importância, na medida em que esta é redigida poucos anos após a tomada de Ceuta pelo exército de D. João I, num contexto em que a guerra marítima, o início da expansão ultramarina e a guerra de conquista no Norte de África faziam parte da actualidade política. Por conseguinte, as ousadas expedições de Fuas Roupinho justificavam historicamente a posterior intervenção bélica portuguesa no Norte de África, no século XV, cujas origens remontariam, assim, à segunda metade do século XII.

\section{Bibliografia}

\section{Fontes}

BASTO, Artur de Magalhães (ed.), Crónica de Cinco Reis de Portugal, Porto, Livraria Civilização, 1945.

BRITO, Frei Bernardo de, Monarquia Lusitana, Segunda Parte, Lisboa, 1609. CALADO, Adelino Almeida (ed.), Crónica de Portugal de 1419, Aveiro, Universidade de Aveiro, 1998.

COSTA, Avelino de Jesus da, e RODRIGUES, Manuel Augusto (ed.), Livro Preto: cartulário da sé de Coimbra: edição crítica: texto integral, Coimbra, Arquivo da Universidade de Coimbra, 1999. 
DURO PEÑA, Emilio (ed.), Documentos da Catedral de Ourense, A Coruña, Consello da Cultura Galega, 1996.

GOMES, Saul António (ed.), Porto de Mós: colectânea histórica e documental: séculos XII a XIX, Porto de Mós, Câmara Municipal, 2005.

HUICI MIRANDA, Ambrosio (trad.), Colección de Crónicas Árabes de la Reconquista, Tomo I: Los Almohades, Vol. II: Al-Bayān Al-Mugrib Fi Ijtisār Ajbār Muluk Al-Andalus Wa Al-Magrib, Tetuán, Editora Marroquí, 1953. PIEL, Joseph, e MATTOSO, José (ed.), Portvgaliae Monvmenta Historica, Vol. II: Livro de Linhagens do Conde D. Pedro, Tomo 2, Nova Série, Lisboa, Academia das Ciências, 1980.

TAROUCA, Carlos da Silva (ed.), Crónicas dos sete primeiros reis de Portugal, Lisboa, Academia Portuguesa de História, 3 vol., 1952-1953.

WALTER, Monica Blöcker (ed.), “Annales D. Alfonsi Portugallensium Regis”, in Alfons I von Portugal: Studien zu Geschichte und Sage des Begrunders der Portugiesische Unbhägigkeit, Zürich, Fretz und Wasmuth Verlag, 1966, p. 151-161.

\section{Estudos}

BARROCA, Mário Jorge, "História das Campanhas", in BARATA, Manuel Themudo, e TEIXEIRA, Nuno Severiano (dir.), Nova História Militar de Portugal, Vol. 1, Lisboa, Círculo de Leitores, 2003, p. 22-68.

BASTO, Artur de Magalhães, Estudos. Cronistas e crónicas antigas. Fernão Lopes e a "Crónica de 1419", Coimbra, Imprensa da Universidade, 1960. BRANCO, Maria João Violante, D. Sancho I: o Filho do Fundador, Lisboa, Círculo de Leitores, 2006.

CINTRA, Luís Filipe Lindley (ed.), "Introdução", in Crónica Geral de Espanha de 1344, Vol. I, Lisboa, Academia Portuguesa de História, 1951.

CONDE, Manuel Sílvio Alves, "Sesimbra, sobre a costa do mar (séculos XII-XIII), Arquipélago-História, 2a série, VII (2003), p. 243-268.

DUARTE, Luís Miguel, "A Marinha de Guerra Portuguesa”, in BARATA, Manuel Themudo, e TEIXEIRA, Nuno Severiano (dir.), Nova História Militar de Portugal, Vol. 1, Lisboa, Círculo de Leitores, 2003, p. 290-346. GUEVARA Y VALDÉS, Eduardo Pardo de, "De las viejas estirpes a las nuevas hidalguías. El entramado nobiliario gallego al fin de la Edad Media", Nalgures, Tomo III (2006), A Coruña, Asociación Cultural de Estudios Históricos de Galicia, p. 265-280.

HERCULANO, Alexandre, História de Portugal, Tomo III, Lisboa, Aillaud-Bertrand, $8^{\text {a }}$ edição, s/d. 
HUICI MIRANDA, Ambrosio, "Los Almohades en Portugal", Anais da Academia Portuguesa de História, II ${ }^{a}$ Série, Vol. 5 (1954), p. 9-51.

-, "Las campañas de Ya'qūb Al-Mansūr en 1190 y 1191", Anais da Academia Portuguesa de História, II ${ }^{a}$ Série, Vol. 5 (1954), p. 53-74.

KRUS, Luís, "Roupinho, Fuas", in PEREIRA, José Costa (coord.), Dicionário Enciclopédico da História de Portugal, Vol. II, Lisboa, Publicações Alfa Selecções do Reader's Digest, 1990, p. 187-188.

-, "Crónica de Portugal de 1419", in LANCIANI, Giulia, e TAVANI, Giuseppe (org. e coord.), Dicionário da Literatura Medieval Galega e Portuguesa, Lisboa, Caminho, 1993, p. 185-186.

MATTOSO, José, Ricos-homens, infanções e cavaleiros: a nobreza medieval portuguesa nos séculos XI e XII, 2a ed., Lisboa, Guimarães Editores, 1985.

-, A nobreza medieval portuguesa: a família e o poder, $4^{\mathrm{a}}$ ed. rev., Lisboa, Estampa, 1994.

-, "Dois séculos de vicissitudes políticas", in MATTOSO, José (dir.), História de Portugal, Vol. 2: A Monarquia Feudal, Lisboa, Editorial Estampa, 1997, p. 25-140.

-, D. Afonso Henriques, Lisboa, Temas \& Debates, 2007.

MOREIRA, Filipe Alves, A Crónica de Portugal de 1419: Fontes, Estratégias e Posteridade, Porto, Faculdade de Letras do Porto, 2010.

PICARD, Christophe, L'océan Atlantique musulman: De la conquête arabe à l'époque almohade, Paris, Maisonneuve \& Larose, 1997.

-, Le Portugal Musulman: VIII ${ }^{e}$-XIII ${ }^{e}$ siècles, Paris, Maisonneuve \& Larose, 2000.

PIMENTA, Maria Cristina, Guerras no Tempo da Reconquista. 1128-1249, Lisboa, Quidnovi, 2008.

SILVA, Maria Fernanda Espinosa Gomes da, "Roupinho, Fuas (século XII)", in SERRÃO, Joel (dir.), Dicionário de História de Portugal, Vol. III, Porto, Livraria Figueirinhas/Iniciativas Editoriais, 1971, p. 696.

SILVA, Tiago João Queimada e, As metamorfoses de um guerreiro: Afonso Henriques na cronística medieval, Coimbra, Faculdade de Letras da Universidade de Coimbra, 2011.

VENTURA, Leontina, e FARIA, Ana Santiago (ed.), "Introdução", in Livro Santo de Santa Cruz: cartulário do Séc. XII, Coimbra, Instituto Nacional de Investigação Científica, 1990, p. 9-68.

VENTURA, Leontina, "Os cavaleiros de Coimbra", comunicação inédita, apresentada ao Colóquio Internacional "Afonso Henriques: em torno da criação e consolidação das monarquias do Ocidente Europeu (sécs. XII- 
-XIII). Identidades e Liminaridades", realizado de 14 a 16 de Dezembro de 2009, na Faculdade de Letras da Universidade de Lisboa.

Recebido: 10/03/12

Aceite: $26 / 04 / 12$ 